\title{
USAHA MEMPERBAIKI WARNA HASIL OVER WEIGHT REDUCE PADA KAIN POLIESTER AGAR SESUAI DENGAN TARGET
}

\author{
Oleh : \\ Ikhwanul Muslim, Ika Natalia Mauliza dan Karlina Somantri \\ Staf Pengajar Sekolah Tinggi Teknologi Tekstil,
}

\begin{abstract}
Weight reduce process to be done on polyester fabric to get the desired result. Sometimes, the process was fail and make the fabric was overweight reduced. It will make the color on the dyeing process are older that the target fabric (on the normal weight reduction), even they're dyed with the same conditions. To solve that problem, to get the same color from the over weight reduced fabric to be same as the target, first stage experiment was done, that compare the K/S value to variations of the dyes concentration against $K / S$ value to variations of the weight reduction percentage. From those results, to be made the graphic between $K / S$ value to variations of the dyes concentration against $K / S$ value to variations of the weight reduction percentage. The result is linear graphic. Using the elimination method, get the linear equation to calculate the needs of the concentration of the dyes on the dyeing process to get the same result as the target.

From the experiments' data, get the equation between dyes concentration ( $Z$ ) against percentage of weight reduction $(X)$ that $24.4 Z=11.2 X+15.34$. The formula was validated by doing experiment on the fabric that weight reduced $12 \%$. From that formula, we calculate the needs of the dyes concentration is $0.726 \%$. Dyeing process was done with $0.726 \%$ dyes concentration on weight reduced fabric $12 \%$ and K/S value is 16.7859 . It's same as K/S value on the target (weight reduced fabric 5\%).
\end{abstract}

\section{INTISARI}

Proses weight reduce dilakukan pada kain poliester untuk mendapatkan hasil yang diinginkan. Terkadang muncul kegagalan proses berupa overweight reduce yang mengakibatkan warna kain hasil pencelupannya lebih tua dari warna kain target (normal weight reduce) yang dicelup menggunakan resep yang sama. Untuk mengatasi masalah tersebut, yaitu mendapatkan warna hasil overweight reduce agar sesuai dengan target, dilakukan percobaan tahap pertama dengan cara membandingkan nilai warna $(\mathrm{K} / \mathrm{S})$ dengan variasi konsentrasi zat warna terhadap nilai warna $(\mathrm{K} / \mathrm{S})$ dengan variasi besarnya weight reduce. Dari kedua hasil tersebut dibuat suatu grafik hubungan antara $\mathrm{K} / \mathrm{S}$ dengan variasi konsentrasi zat warna dan $\mathrm{K} / \mathrm{S}$ dengan variasi weight reduce. Sehingga jika hasil tersebut merupakan suatu grafik garis lurus, maka dapat dibuat persamaan garis lurus antara harga $\mathrm{K} / \mathrm{S}$ dengan variasi konsentrasi zat warna dan harga $\mathrm{K} / \mathrm{S}$ dengan variasi weight reduce. Dari kedua persamaan tersebut, dengan metoda eliminasi dapat dihasilkan persamaan 
garis lurus untuk menghitung berapa konsentrasi zat warna yang dibutuhkan untuk mendapatkan warna hasil weight reduce yang sesuai dengan permintaan. Setelah didapatkan data percobaan, maka diperoleh persamaan antara konsentrasi zat warna $(Z)$ dengan weight reduce $(X)$ yaitu 24.,4 $Z=11,2 X+$ 15,34 . Dilakukan pengujian validasi formula yang didapat terhadap kain dengan weight reduce $12 \%$. Dari formula tersebut dapat dihitung bahwa konsentrasi zat warna yang diperlukan adalah sebesar $0.726 \%$ agar didapatkan warna sesuai target (WR 5\%). Dilakukan pencelupan dengan konsentrasi zat warna 0,726 \% terhadap kain hasil weight reduce $12 \%$ dan didapat nilai K/S bahan sebesar 16,7859 . Hal ini sesuai dengan nilai K/S hasil weight reduce target $(5 \%)$.

\section{PENDAHULUAN}

Serat poliester merupakan serat buatan yang sangat populer di dunia. Dipakai di berbagai industri khususnya tekstil. Serat ini dibentuk oleh rantai polimer panjang, dengan komposisi berupa ester yang dibentuk dari asam tereftalat dan etilena glikol. Polimer poliester yang paling banyak digunakan, seperti Polyethylene-terepthalate, atau yang lebih dikenal dengan PET, diproduksi secara komersial dalam dua tahap polimerisasi, yaitu pembentukan monomer ester melalui reaksi esterifikasi pada asam tereftalat dengan etilena glikol, kemudian diikuti dengan reaksi polikondensasi. Dengan proses polimerisasi, serat kemudian dipintal dengan cara pemintalan leleh (melt spinning). Serat poliester memiliki kekuatan 4,5-7 g/denier dan mulur antara 40-11\%. Kekuatan dan mulur serat poliester dalam keadaan basah maupun kering tidak ada perbedaan yang berarti karena sifatnya yang hidrofob. Memiliki titik leleh sekitar $250-300^{\circ} \mathrm{C}$. Tahan alkali kuat pada suhu ruang dan semakin lemah (terdegradasi) seiring peningkatan suhu. Dalam alkali lemah menunjukkan ketahanan baik pada temperatur ruang maupun temperatur tinggi.

Zat warna dispersi merupakan zat warna organik yang dibuat secara sintetik. Berat molekul kecil dan tidak punya gugus pelarut, sehingga kelarutannya dalam air kecil sekali. Zat warna dispersi biasa digunakan untuk mewarnai serat sintetik sebagai zat warna terdispersi di dalam larutan, dimana ditambahkan dispersing agent anionik ke dalamnya. Secara umum, zat warna dispersi memiliki karakteristik yaitu : Mempunyai berat molekul yang rendah dengan inti kromofor azo, antrakuinon atau difenilamina. Meleleh pada temperatur tinggi $\left(>150^{\circ} \mathrm{C}\right.$ ), kemudian dapat mengkristal lagi. Pada dasarnya nonionik, mempunyai gugus aromatik dan/atau alifatik $\left(-\mathrm{OH},-\mathrm{NH}_{2},-\mathrm{NHR}\right.$, dst.) sebagai donor hidrogen untuk mengadakan ikatan dengan gugus karbonil pada serat. Zat warna dispersi sedikit larut dalam air $( \pm 0,1$ miligram/L). Mempunyai tingkat kejenuhan tinggi (30-200 mg zat warna murni per gram serat). Penambahan zat pendispersi ke dalam larutan celupnya menyebabkan dispersi yang stabil dalam air, tidak ada perubahan kimia yang disebabkan oleh proses pencelupannya. Zat warna dispersi Foron merupakan zat warna dispersi untuk mencelup serat poliester dan campurannya. Zat warna ini diproduksi oleh Clariant (Australia) Pty Ltd. Contoh zat warna dispersi dengan merek dagang Clariant tersebut adalah C.I. Disperse Yellow 235 atau dikenal dengan nama Foron Yellow RD-4GRL. Foron RD (rapid dyeing) adalah zat warna dispersi yang dikembangkan untuk mencelup serat poliester pada suhu dan tekanan tinggi. 
Proses pengurangan berat pada serat poliester didasarkan pada sifat kimia serat poliester yang terhidorlisis oleh alkali kuat terutama bila dikerjakan pada suhu dan tekanan tinggi. Reaksi hidrolisis secara lengkap adalah dapat dilihat pada gambar no.1.1 berikut.

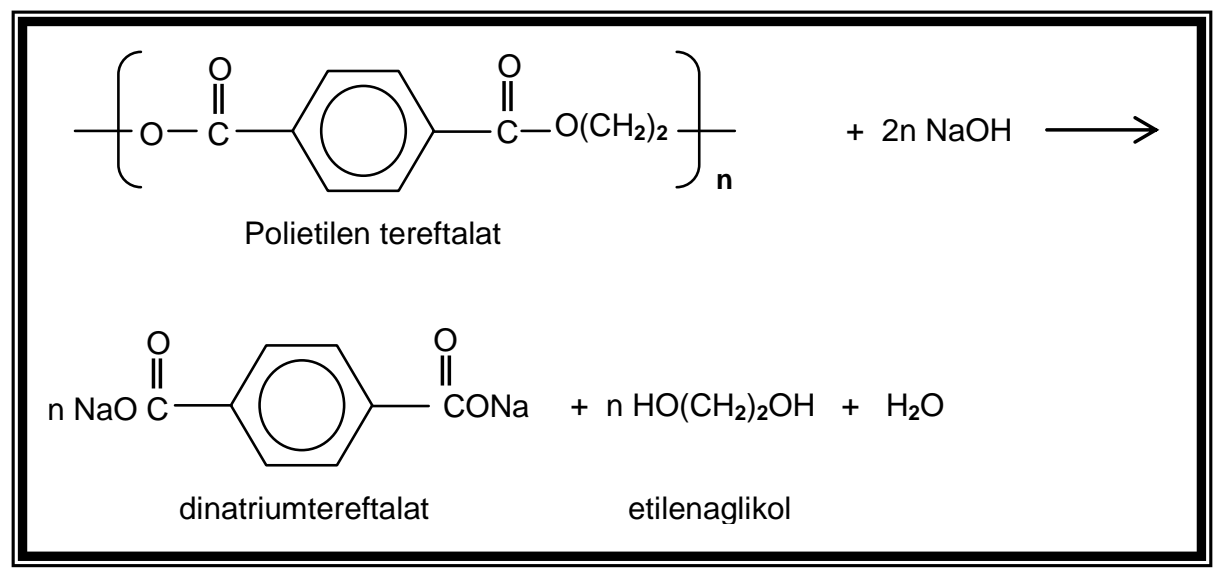

Gambar no.1.1 Reaksi Hidrolisis serat Poliester oleh alkali kuat $(\mathrm{NaOH})$.

Prinsip pengerjaan ini adalah hidrolisa permukaan serat poliester oleh kostik soda sehingga mengakibatkan pengikisan permukaan dan pengurangan berat. Semakin besar persentase pengurangan berat, semakin lemas pula kain yang dihasilkan, sampai berat tertentu (maksimal 20\% pengurangan berat), selebihnya kekuatan tarik kain yang dihasilkan tidak memenuhi persyaratan untuk tujuan akhir penggunaan kain tersebut.

Proses ini tidak dapat berjalan lebih lanjut bila natrium hidroksida yang ada telah habis dipakai untuk reaksi hidrolisa pada serat poliester. Dari reaksi yang terjadi secara teori, jumlah $\mathrm{NaOH}$ yang dibutuhkan untuk mendapatkan besarnya persen pengurangan berat (\%WR) dapat dihitung menurut persamaan.

$$
\begin{array}{ll}
\% \mathrm{WR} & =192 / 80 \times \% \mathrm{NaOH} \text { (dari berat bahan) } \\
192 & =\text { berat satu molekul poliester } \\
80 & =\text { berat dua molekul } \mathrm{NaOH}(2 \times \mathrm{BM})
\end{array}
$$

Faktor-faktor yang mempengaruhi proses pengurangan berat adalah :

1. Temperatur: Temperatur merupakan elemen kontrol penting pada proses pengurangan berat, karena kecepatan pengikisan bahan akan bertambah dengan kenaikan temperatur sehingga persen pengurangan berat semakin besar.

2. Konsentrasi $\mathrm{NaOH}$ : Faktor ini merupakan kontrol penting berikutnya dalam proses pengurangan berat. Hampir dapat dipastikan bahwa perbedaan konsentrasi $\mathrm{NaOH}$ yang digunakan akan memberikan perbedaan persen pengurangan berat yang mencolok. Kenaikan konsentrasi $\mathrm{NaOH}$ akan meningkatkan jumlah $\mathrm{NaOH}$ yang bereaksi dengan serat. 
3. Waktu : Persen pengurangan berat akan meningkat dengan penambahan waktu proses, karena waktu proses yang semakin lama akan memberikan peluang yang lebih banyak pada $\mathrm{NaOH}$ untuk bereaksi dengan serat. Dalam kegiatan produksi, waktu sering diatur sedemikian rupa agar waktu produksi lebih singkat tetapi jumlah produksi meningkat dan biaya produksi berkurang. Untuk mendapatkan persen pengurangan berat yang besar dalam waktu singkat, bisa saja dilakukan dengan meningkatkan temperatur proses dan konsentrasi $\mathrm{NaOH}$ atau dengan penambahan zat pembantu dengan batas tertentu.

4. Perbandingan larutan : Perbandingan larutan di sini adalah perbandingan antara berat bahan dengan jumlah larutan yang digunakan untuk proses. Pemakaian perbandingan larutan yang besar menyebabkan persentase pengurangan berat yang lebih kecil dibandingkan dengan pemakaian perbandingan larutan yang kecil jika variabel yang lain dianggap sama.

5. Katalis : Pengerjaan pengurangan berat dengan penambahan katalis memberikan persen pengurangan berat lebih besar dibandingkan dengan tanpa menggunakan katalis. Ini berarti pengerjaan pengurangan berat dapat dipercepat dengan bantuan penambahan katalis.

6. Jenis bahan : Tidak semua serat poliester mempunyai respon yang sama terhadap $\mathrm{NaOH}$. Serat poliester yang mengkilap dengan penampang melintang yang bulat memiliki ketahan terhadap $\mathrm{NaOH}$ yang lebih baik dibandingkan serat poliester yang suram dan berpenampang multilobal. Benang tekstur mempunyai respon yang lebih cepat dibandingkan dengan benang yang keras. Kain yang telah diproses kalander tampak mempunyai pengaruh yang lebih tinggi terhadap hidrolisis $\mathrm{NaOH}$ di daerah kritisnya. Pada daerah ini menimbulkan penetrasi yang lebih besar.

Pengaruh overweight reduce pada poliester terlihat jelas pada perubahan warna kainnya. Warna kain hasil overweight reduce berbeda dengan warna kain hasil weight reduce. Sehingga sebagai langkah awal untuk memperbaiki warna hasil overweight reduce diperlukan data nilai/harga K/S.

Harga K/S akan semakin besar seiring dengan penambahan konsentrasi zat warna. Dan overweight reduce menyebabkan harga K/S berubah secara linear. Dari kedua data tersebut maka untuk menentukan warna kain hasil overweight reduce dapat digunakan model persamaan garis lurus $(\mathrm{Y}-\mathrm{Y} 1) /(\mathrm{Y} 2-\mathrm{Y} 1)=(\mathrm{X}$ $\mathrm{X} 1) /(\mathrm{X} 2-\mathrm{X} 1)$ antara harga $\mathrm{K} / \mathrm{S}$ dengan konsentrasi zat warna dengan harga $\mathrm{K} / \mathrm{S}$ dengan weight reduce. 
Jika diasumsikan harga $\mathrm{K} / \mathrm{S}=\mathrm{Y}$, variasi konsentrasi zat warna $=Z$, dan variasi weight reduce $=\mathrm{X}$, didapat 2 persamaan antara $\mathrm{Y}$ terhadap $\mathrm{X}$ dan $\mathrm{Y}$ terhadap $\mathrm{Z}$, sebagai berikut :

$$
\begin{array}{r}
((\mathrm{Y}-\mathrm{Y} 1) /(\mathrm{Y} 2-\mathrm{Y} 1))=((\mathrm{X}-\mathrm{X} 1) /(\mathrm{X} 2-\mathrm{X} 1)) \\
\operatorname{dan} \\
((\mathrm{Y}-\mathrm{Y} 1) /(\mathrm{Y} 2-\mathrm{Y} 1))=((\mathrm{Z}-\mathrm{Z} 1) /(\mathrm{Z} 2-\mathrm{Z} 1))
\end{array}
$$

Setelah diperoleh dua persamaan garis lurus, maka dengan metoda eliminasi dua persamaan $(Y=Y)$, dapat diperoleh persamaan garis lurus yang menyatakan hubungan antara variasi konsentrasi zat warna $(Z)$ dengan variasi weight reduce $(\mathrm{X})$, sehingga dapat digunakan untuk menentukan berapa konsentrasi zat warna yang dibutuhkan bila terjadi overweight reduce.

\section{PERCOBAAN}

Percobaan dilakukan untuk memperoleh konsentrasi zat warna untuk pencelupan kain poliester (high twist) yang mengalami over weight reduce agar didapat ketuaan warna yang sesuai dengan target.

Bahan yang digunakan untuk percobaan ini adalah sebagai berikut :

1. Kain tenun poliester (high twist) yang telah mengalami proses pemasakan, penghilangan kanji, relaksasi dan pemantapan panas dengan spesifikasi sebagai berikut :

- jenis anyaman : keper $3 / 2 / 2$

- nomor benang lusi : $240 \mathrm{D}-96 \mathrm{~F}$

- nomor benang pakan : $150 \mathrm{D}-48 \mathrm{~F}$

- twist benang lusi $\quad: 1200 \mathrm{~S}$ tpm

- twist benang pakan : :1800 S tpm

- tetal lusi $\quad: 163$ helai $/ \mathrm{cm}$

- tetal pakan $\quad: 86$ helai $/ \mathrm{cm}$

- lebar kain $\quad: 151 \mathrm{~cm}$

- berat $\quad: 285 \mathrm{~g} / \mathrm{m}^{2}$

2. Natrium hidroksida $(\mathrm{NaOH})$ untuk menghidrolisa poliester sehingga terjadi proses pengurangan berat.

3. Foryl DSB untuk meningkatkan daya pembasahan kain.

4. Asam asetat $\left(\mathrm{CH}_{3} \mathrm{COOH}\right) 98 \%$ untuk menetralkan hasil proses pengurangan berat

5. Zat warna dispersi Foron Yellow RD-4DRL untuk mewarnai kain secara merata \& permanen.

6. Sunsolt YKDB untuk mendispersikan zat warna dalam larutan celup.

7. BF 3359 untuk melepas kotoran dan meningkatkan daya pembasahan kain saat cuci. 
Resep pengurangan berat :

$\mathrm{NaOH}($ flake $)=30 \mathrm{~g} / \mathrm{l}$

Vlot $\quad=1: 10$

Suhu $\quad=93^{\circ} \mathrm{C}$

Waktu = variasi untuk mendapatkan nilai pengurangan berat yang diinginkan

\begin{tabular}{|c|c|c|c|c|}
\hline \multirow{2}{*}{ WR } & Normal WR (\%) & \multicolumn{3}{|c|}{ Over WR (\%) } \\
\hline & Variasi 1 & Variasi 2 & Variasi 3 & Variasi 3 \\
\hline Initial stage & $5 \%$ & $10 \%$ & $15 \%$ & $20 \%$ \\
\hline
\end{tabular}

Catatan : Kain variasi 1 (WR 5\%) adalah target pengurangan berat dan variasi 2,3,4 (WR 10,15,20

$\%$ ) adalah kain yang overweight reduce (OWR).

Keempat kain hasil pengurangan berat kemudian dipotong dan ditimbang dengan berat masing-masing 2,5 gram (dibuat sebanyak 24 buah untuk 6 kali pencelupan dengan variasi konsentrasi zat warna dispersi).

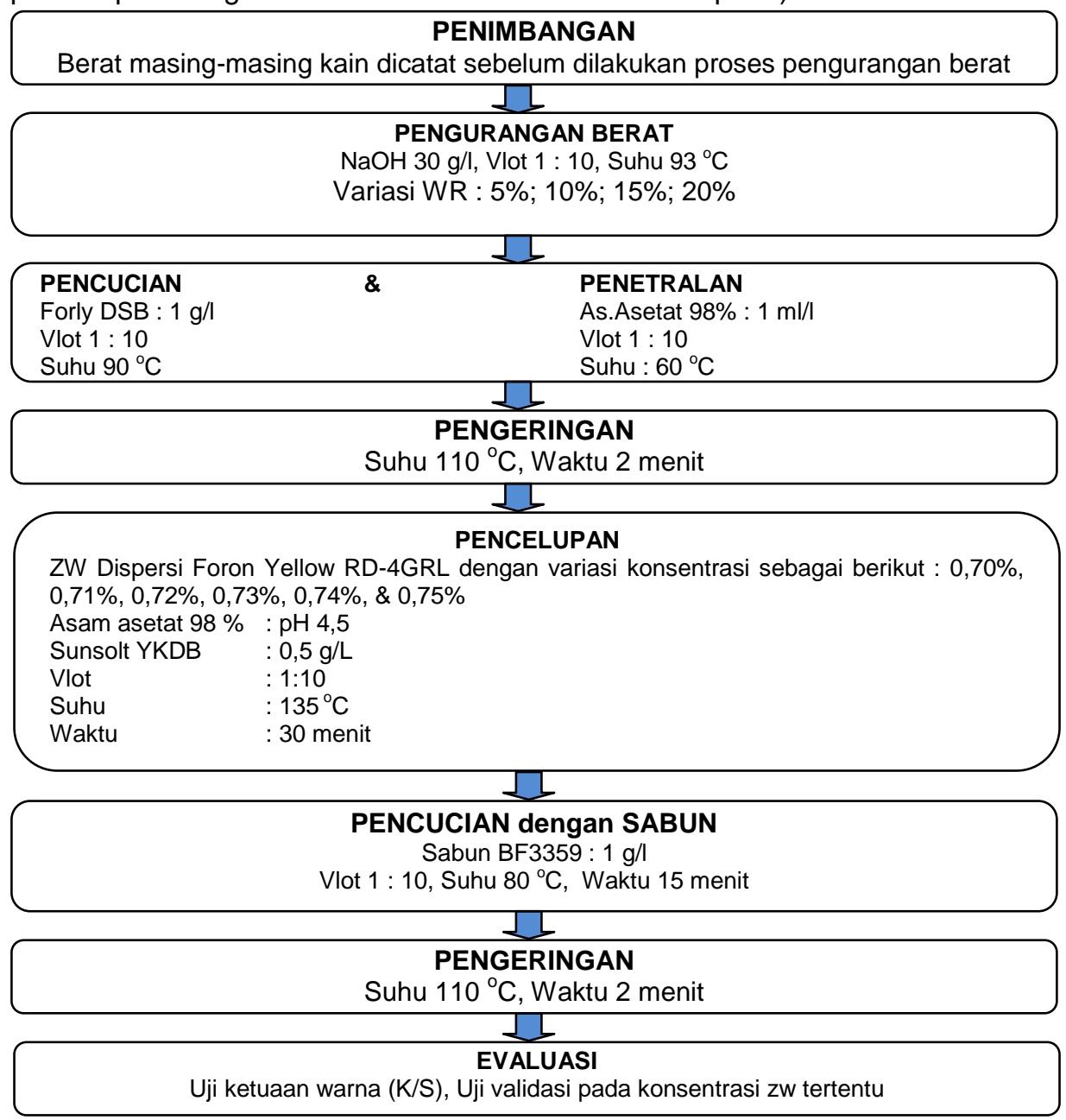

Gambar no.2.1 Diagram Alir Proses Pengurangan Berat pada Poliester. 


\section{HASIL \& PEMBAHASAN}

Dari proses pengurangan berat diperoleh hasil tertera pada tabel no.3.1 berikut :

\begin{tabular}{|c|c|c|c|c|}
\hline \multirow{2}{*}{ Kain } & $\begin{array}{c}\text { Berat awal } \\
(\text { gram })\end{array}$ & \multicolumn{2}{|c|}{ Pengurangan berat (\%) } & \multirow{2}{*}{$\begin{array}{c}\text { Berat akhir } \\
\text { (gram) }\end{array}$} \\
\cline { 3 - 4 } & Aktual & pembulatan & 380.1 \\
\hline 1 & 400.0 & 4.98 & 5 & 360.1 \\
\hline 2 & 400.0 & 9.98 & 10 & 339.9 \\
\hline 3 & 400.0 & 15.01 & 15 & 320.1 \\
\hline 4 & 400.0 & 19.99 & 20 & \\
\hline
\end{tabular}

Tabel no.3.1 Kain Hasil Proses Pengurangan Berat.

Dari proses pencelupan diperoleh hasil nilai ketuaan warna $(\mathrm{K} / \mathrm{S})$ pada tabel no.3.2 berikut :

\begin{tabular}{|c|c|c|c|c|c|}
\hline \multicolumn{6}{|c|}{ Nilai K/S ZW } \\
\hline \multirow{2}{*}{\multicolumn{2}{|c|}{$\begin{array}{l}\text { Nilai K/S ZW } \\
\text { pada bahan }\end{array}$}} & \multicolumn{4}{|c|}{ Pada \% Pengurangan Berat } \\
\hline & & $5 \%$ (target) & $\begin{array}{c}10 \% \\
\text { (OWR) }\end{array}$ & $\begin{array}{c}15 \% \\
\text { (OWR) }\end{array}$ & $20 \%(\mathrm{OWR})$ \\
\hline \multirow{6}{*}{$\begin{array}{l}\text { Kons. } \\
\text { ZW }\end{array}$} & $0,70 \%$ & 15.9072 & 16.4819 & 17.0498 & 17.5893 \\
\hline & $0,71 \%$ & 16.1613 & 16.7879 & 17.3838 & 17.8003 \\
\hline & $0,72 \%$ & 16.5451 & 17.2528 & 17.5898 & 18.0164 \\
\hline & $0,73 \%$ & 16.7962 & 17.4953 & 18.0135 & 18.1893 \\
\hline & $0,74 \%$ & 16.9893 & 17.6638 & 18.3128 & 18.4634 \\
\hline & $0,75 \%$ & 17.1212 & 18.0419 & 18.6178 & 18.8836 \\
\hline
\end{tabular}

Tabel no.3.2 Nilai K/S Hasil Proses Pengurangan Berat.

Kedua tabel diatas memperlihatkan nilai ketuaan warna pada kain poliester dengan pengurangan berat $5 \%, 10 \%, 15 \%$ dan $20 \%$ yang dicelup menggunakan zat warna dispersi Foron Yellow RD-4GRL dengan konsentrasi 0,70\%, 0,71\%, $0,72 \%, 0,73 \%, 0,74 \%$, dan $0,75 \%$. Dari tabel tersebut dapat diketahui adanya kecenderungan kenaikan nilai ketuaan warna dengan semakin besarnya persen pengurangan berat. Secara lebih jelas, nilai-nilai tersebut digambarkan dalam bentuk grafik no.3.1 dibawah ini. 


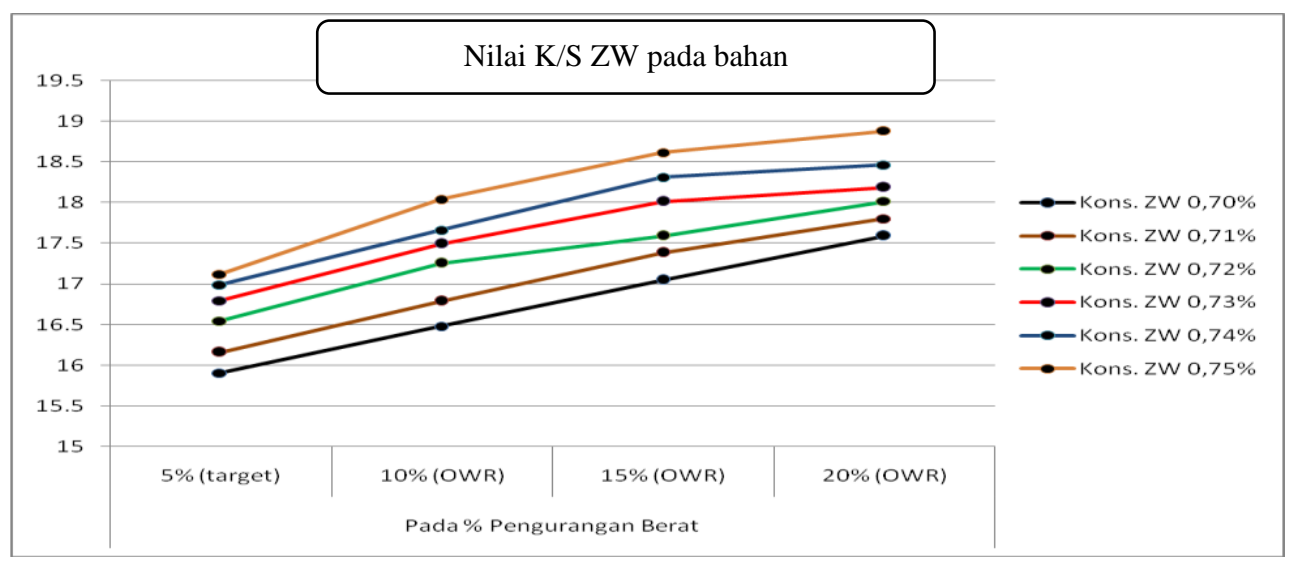

Grafik no.3.1 Nilai K/S Hasil Proses Pengurangan Berat.

Hal ini terjadi karena makin tinggi persen pengurangan berat, diameter permukaan serat akan semakin kecil. Ketidateraturan rantai molekul semakin banyak sehingga memungkinkan zat warna untuk lebih banyak masuk ke serat, akibatnya harga K/S makin besar. Dengan demikian, warna yang terjadi terkesan makin tua. Untuk memperoleh ketuaan warna yang sama dengan target, maka kain yang mengalami over weight reduce diperlukan pengurangan konsentrasi zat warna. Dari grafik hubungan persen pengurangan berat dengan ketuaan warna untuk beberapa konsentrasi zat warna, konsentrasi zat warna yang harus digunakan untuk pencelupan dapat ditentukan asalkan K/S target dan persen pengurangan berat yang terjadi telah diketahui. Caranya dengan menentukan formulasi yang tepat berdasarkan persamaan garis lurus antara $\mathrm{K} / \mathrm{S}$ zat warna dengan konsentrasi zat warna dan $\mathrm{K} / \mathrm{S}$ zat warna dengan \% pengurangan berat. Dengan rumus persamaan garis lurus yaitu :

$(y-y 1) /(y 2-y 1)=(x-x 1) /(x 2-x 1)$

Maka diperoleh 2 persamaan yaitu :

$\mathrm{K} / \mathrm{S}$ dengan konsentrasi zat warna

$\mathrm{Y}=24,4 \mathrm{Z}-1,18$

$\mathrm{K} / \mathrm{S}$ dengan $\%$ pengurangan berat

$Y=0,12 X+15,34$

Dari kedua rumus tersebut diperoleh hubungan antara konsentrasi zat warna dengan \% pengurangan berat adalah :

$24,4 Z=0,12 X+16,52$

Dimana : $\quad Z=$ konsentrasi zat warna $(\%)$

$\mathrm{X}=$ pengurangan berat kain (\%)

$\mathrm{Y}=$ nilai $\mathrm{K} / \mathrm{S}$ bahan 
Dari formula diatas maka kita dapat menera berapa konsentrasi zat warna yang dibutuhkan jika terjadi over weight reduce pada kain. Kemudian dilakukan pengujian validasi untuk membuktikan akurasi dari formula tersebut. Pengujian validasi dilakukan dengan kain yang sudah dianggap over weight reduce dengan \% pengurangan beratnya $12 \%$, lalu dari rumus dapat dihitung bahwa diperlukan konsentrasi zat warna sebesar 0,726 \% agar mendapatkan warna sesuai target ( WR 5\%). Kemudian dilakukan pencelupan dengan konsentrasi zat warna $0,726 \%$ dan didapat nilai K/S bahan sebesar 16,7859.

Penelitian ini dibatasi pada kain poliester (high twist) dengan zat warna dispersi Foron Yellow RD-4GRL untuk warna sedang, yaitu konsentrasi zat warna dari $0,70 \%-0,75 \%$. Pengujian terhadap hasil pencelupan juga dibatasi pada uji ketuaan warna saja. Penelitian ini dapat dilanjutkan dengan corak kain dan zat warna lain untuk warna muda maupun tua. Pengujian terhadap hasil pencelupan juga dapat dilanjutkan dengan pengujian beda warna.

\section{KESIMPULAN}

Dari hasil penelitian dan diskusi yang dilakukan, maka dapat diambil kesimpulan sebagai berikut :

1. Semakin besar persen pengurangan berat, warna hasil pencelupan semakin tua.

2. Untuk mendapatkan ketuaan warna sesuai sama dengan target, maka kain dengan persen pengurangan berat lebih besar memerlukan pengurangan konsentrasi zat warna dari target.

3. Grafik hubungan persen pengurangan berat dengan $\mathrm{K} / \mathrm{S}$ zat warna pada beberapa konsentrasi zat warna dapat dipakai sebagai acuan untuk membuat formula hubungan antara \% overweight reduce dengan \% konsentrasi zat warna dan didapat $24,4 Z=0,12 X+16,52$.

Pengecekan ketepatan konsentrasi zat warna dalam pencelupan (untuk kain dengan persen pengurangan berat $12 \%$ ) berdasarkan formula telah memenuhi target. 


\section{DAFTAR PUSTAKA}

1. Edward, J. L, Advances in Textile Processing Vol.I, Textile Book Publisher Inc., 1961.

2. Houser, Kenneth D, Caustic Reduction of Polyester Fabrics, Malliand vol. 15, No.4, April 1983.

3. Mc. Graw, Tata, Fibre Science and Technolgy, Hill Publishing Company Limited, New Delhi, August 15, 2003.

4. Moncrieff, R. W, Man Made Fibres, Sixth Edition, Newness-Butterworth, London, 1975.

5. Needles, H. L, et al, The Dyeing and Colour Characteristics of AlkaliTreated Polyester Fibres Dyed with Disperse Dyes, JSDC, Volume 10, December 1990.

6. Niu, Shouhua, and Wakida, Tomiji, Effect of Heat Setting Temperature on Alkali Hydrolysis of Poly(Ethylena Terephtalate) Fibers, Textile Res. J. 63 (6), 346-350, 1993.

7. Venkataraman, K, The Analytical Chemistry of Synthethic Dyes V, National Chemical Laboratory Poona, India, 1976.

8. Technical Information Foron RD, Clariant.

9. Safety Data Sheet in Accordance with 2001/58/EC, Foron Yellow RD-4GRL, Clariant, 2006. 